\title{
Correction to: Deep user identification model with multiple biometric data
}

\author{
Hyoung-Kyu Song ${ }^{1}$, Ebrahim AlAlkeem ${ }^{2,3}$, Jaewoong Yun ${ }^{4}$, Tae-Ho Kim ${ }^{5}$, Hyerin Yoo ${ }^{4}$, Dasom Heo ${ }^{4}$, \\ Myungsu Chae $e^{4}$ and Chan Yeob Yeun ${ }^{2,3^{*}}$
}

From The 13th International Workshop on Data and Text Mining in Biomedical Informatics

Beijing, China. 3-7 November 2019

\author{
The original article can be found \\ online at https://doi.org/10.1186/ \\ s12859-020-03613-3. \\ * Correspondence: chan.yeun@ku. \\ ac.ae \\ ${ }^{2}$ Electrical Engineering and \\ Computer Science Department, \\ Khalifa University of Science and \\ Technology, Abu Dhabi, United \\ Arab Emirates \\ ${ }^{3}$ Center for Cyber-Physical Systems, \\ Khalifa University of Science and \\ Technology, Abu Dhabi, United \\ Arab Emirates \\ Full list of author information is \\ available at the end of the article
}

\section{Correction to: BMC Bioinformatics 21, 315 (2020) https://doi.org/10.1186/s12859-020-03613-3}

Following publication of the original article [1], it was reported that the article entitled "Deep user identification model with multiple biometric data" was published in the regular issue of this journal instead of in the supplement issue.

The details of the supplement in which this article ought to have been published are given below:

\section{About this supplement}

This article has been published as part of BMC Bioinformatics, Volume 21 Supplement 5, 2020: Proceedings of the 13th International Workshop on Data and Text Mining in Biomedical Informatics (DTMBIO 2019). The full contents of the supplement are available at https://bmcbioinformatics.biomedcentral.com/articles/supplements/volume-21-supplement-5.

The publisher apologises for any inconvenience caused.

\begin{abstract}
Author details
${ }^{1}$ Korea Advanced Institute of Science and Technology, Daejeon, South Korea. ${ }^{2}$ Electrical Engineering and Computer Science Department, Khalifa University of Science and Technology, Abu Dhabi, United Arab Emirates. ${ }^{3}$ Center for Cyber-Physical Systems, Khalifa University of Science and Technology, Abu Dhabi, United Arab Emirates. ${ }^{4}$ Research Institute, NOTA Incorporated, Gangnam-gu, Seoul, South Korea. Institute for Artificial Intelligence, Korea Advanced Institute of Science and Technology, Daejeon, South Korea.
\end{abstract}

Received: 30 January 2020 Accepted: 6 February 2020 Published: 26 October 2020

\section{Reference}

1. Song H, AlAlkeem E, Yun J, et al. Deep user identification model with multiple biometric data. BMC Bioinformatics. 2020;21:315 https://doi.org/10.1186/s12859-020-03613-3.

\section{$\triangle B M C$}

(0) The Author(s). 2020 Open Access This article is licensed under a Creative Commons Attribution 4.0 International License, which permits use, sharing, adaptation, distribution and reproduction in any medium or format, as long as you give appropriate credit to the original author(s) and the source, provide a link to the Creative Commons licence, and indicate if changes were made. The images or other third party material in this article are included in the article's Creative Commons licence, unless indicated otherwise in a credit line to the material. If material is not included in the article's Creative Commons licence and your intended use is not permitted by statutory regulation or exceeds the permitted use, you will need to obtain permission directly from the copyright holder. To view a copy of this licence, visit http://creativecommons.org/licenses/by/4.0/. The Creative Commons Public Domain Dedication waiver (http://creativecommons.org/publicdomain/zero/1.0/) applies to the data made available in this article, unless otherwise stated in a credit line to the data. 